\title{
Exposure of a Corneal Epithelial Cell Line (hTCEpi) to Demodex-Associated Bacillus Proteins Results in an Inflammatory Response
}

\author{
Frederick W. McMahon, ${ }^{1}$ Clair Gallagher, ${ }^{2}$ Niamh O'Reilly, ${ }^{1}$ Martin Clynes, ${ }^{2}$ Finbarr O'Sullivan, ${ }^{2}$ \\ and Kevin Kavanagh ${ }^{1}$
}

${ }^{1}$ Department of Biology, National University of Ireland Maynooth, County Kildare, Ireland

${ }^{2}$ National Institute for Cellular Biotechnology, Dublin City University, Glasnevin, Dublin, Ireland

Correspondence: Kevin Kavanagh, Department of Biology, NUI Maynooth, County Kildare, Ireland; kevin.kavanagh@nuim.ie.

Submitted: June 13, 2014

Accepted: September 17, 2014

Citation: McMahon FW, Gallagher C, O'Reilly N, Clynes M, O'Sullivan F, Kavanagh K. Exposure of a corneal epithelial cell line (hTCEpi) to Demodex-associated Bacillus proteins results in an inflammatory response. Invest Ophthalmol Vis Sci. 2014;55:7019-7028. DOI:10.1167/ iovs.14-15018

\begin{abstract}
Purpose. A role for a bacterium, Bacillus oleronius, originally isolated from a Demodex mite, in the induction of ocular rosacea has been proposed. The aim of this work was to characterize the response of a corneal epithelial cell line to Bacillus proteins, as this might give an insight into how such proteins contribute to the symptoms of ocular rosacea in vivo.

Methods. The effect of exposing Bacillus protein preparation on human telomeraseimmortalized corneal epithelial cells (hTCEpi) was measured by monitoring changes in cell proliferation and the expression of a number of genes associated with inflammation. The production of inflammatory cytokines was measured and the expression and activity of MMP9 was quantified.
\end{abstract}

REsults. Exposure of hTCEpi cells to 2 or $6 \mu \mathrm{g} / \mathrm{mL}$ Bacillus protein resulted in a dosedependent reduction in cell proliferation. Exposure of cells to $6 \mu \mathrm{g} / \mathrm{mL}$ Bacillus protein did not induce apoptosis, but there was an increase in the expression of genes coding for IL-6 (13.8-fold), IL-1 $\beta$ (4.0-fold), IL-8 (11.1-fold), and TNF- $\alpha$ (4.1-fold). Increased expression of genes coding for the defensins, CCL20 (4.5-fold) and S100A7 (6.8-fold) also was observed. Elevated production of IL- 6 and IL- 8 was evident from cells exposed to 2 and $6 \mu \mathrm{g} / \mathrm{mL}$ Bacillus protein. The hTCEpi cells demonstrated increased MMP-9 expression (3.2-fold, $P=0.003$ ) and activity (2.2-fold, $P=0.0186$ ) after 48 hours of exposure to $6 \mu \mathrm{g} / \mathrm{mL}$ Bacillus protein preparation.

Conclusions. The results suggest that interaction of Demodex-associated Bacillus proteins with the corneal surface could lead to tissue degradation and inflammation, possibly leading to corneal scarring.

Keywords: Bacillus, corneal surface, corneal scarring, Demodex, ocular rosacea, sterile ulcers

\section{$\mathbf{R}$} osacea is a chronic inflammatory dermatological condition that predominantly affects the skin of the face and the eyes. ${ }^{1,2}$ It is estimated that the condition affects approximately $3 \%$ of the population and there are at least 14 million sufferers in the United States. A number of forms of rosacea are recognized, including papulopustular, erythematotelangiectatic, ocular, and phymatous. ${ }^{3}$ Ocular rosacea affects the eyes and the eyelids, causing symptoms such as blepharitis and keratitis, and up to half of those diagnosed with facial rosacea also manifest ocular symptoms. ${ }^{4,5}$ Corneal (sterile) ulcers and corneal scarring are associated with severe cases of ocular rosacea and can lead to a deterioration in vision and potentially blindness in affected eyes. ${ }^{6}$ Although the classification of rosacea is now well established, there is no agreement on its etiology. A number of factors have been implicated in the induction and persistence of rosacea, including alterations in the immune response, increased dermal vascularization, and the presence of reactive oxygen species in the skin. ${ }^{7}$

Patients affected with rosacea display a higher density of facial mites, Demodex folliculorum, than unaffected controls, ${ }^{8-11}$ although the significance of this observation has never been fully explained. Elevated numbers of Demodex mites also are present on the eyelashes of patients with ocular rosacea. ${ }^{12}$

A potential role for bacteria in the induction of rosacea has been suggested, because antibiotics (e.g., erythromycin, metronidazole) can be used to treat the condition, although these may also exhibit anti-inflammatory properties. ${ }^{2,13}$ Staphylococcus epidermidis isolated from rosacea patients were consistently $\beta$-hemolytic and grew better at $37^{\circ} \mathrm{C}$ than $30^{\circ} \mathrm{C}$, suggesting a potential link between mesophilic hydrolytic bacteria and rosacea. ${ }^{14}$ This bacterium also has been isolated from the pustules of patients with papulopustular rosacea and from the eyelids of patients with ocular rosacea, suggesting a possible role for this bacterium in the induction of these conditions. ${ }^{15}$ A bacterium (Bacillus oleronius), originally isolated from a Demodex folliculorum mite from a patient with papulopustular rosacea, produced proteins that induced an inflammatory immune response in $72 \%$ of rosacea patients but only $29 \%$ of controls $(P=0.01){ }^{16}$ This bacterium also has been isolated from the eyelashes of patients with blepharitis ${ }^{17}$ and is sensitive to the antibiotics used to treat rosacea. ${ }^{16} \mathrm{~A}$ strong correlation has been established between ocular Demodex inflammation and serum reactivity to these bacterial 
proteins in patients with ocular rosacea. ${ }^{12}$ In addition, the presence of eyelid margin inflammation $(P=0.04)$ and facial rosacea $(P=0.009)$ correlated with reactivity to these proteins. ${ }^{12}$ Neutrophils exposed to Bacillus proteins demonstrated increased migration and elevated release of MMP-9, an enzyme known to degrade collagen, and cathelicidin, an antimicrobial peptide. Exposure of neutrophils to the bacterial proteins resulted in elevated production of IL- 8 and TNF- $\alpha .{ }^{18}$ Increased production of IL-8 is a trigger for neutrophil recruitment to the site of infection, and TNF- $\alpha$ is indicative of an inflammatory response. These studies suggest a possible role for bacterial proteins in the etiology of rosacea. ${ }^{12,16,18}$

Human telomerase-immortalized corneal epithelial cells (hTCEpi) are an excellent model for studying the response of the corneal surface to pathogens or pathogen-derived materials (e.g., toxins, antigens) and may give an insight into the response of the cornea to bacterial interactions in ocular rosacea. Human telomerase-immortalized corneal epithelial cells have previously been used to study the interaction of flagellin from pathogenic and nonpathogenic bacteria, ${ }^{19}$ and in understanding the response of the corneal surface to the combined effect of contact lens and Pseudomonas aerugino$s a .^{20}$

In a previous study, we characterized the response of the hTCEpi cells to Bacillus proteins in terms of alterations in cell migration and invasiveness. ${ }^{21}$ The results indicated increased cell migration and invasiveness after exposure of the cells to the Bacillus proteins. Cells exposed to Bacillus proteins showed a dose-dependent increased expression of genes coding for matrix metalloproteinase-3 (MMP-3) (61-fold) and MMP-9 (300-fold). This dose-dependent increase in gene expression also was reflected in elevated levels of MMP-9 protein and increased MMP activity in the culture supernatant. These results suggest a possible link between exposure to Bacillus proteins and the development of corneal damage in ocular rosacea patients. The aim of present work was to characterize whether exposure of hTCEpi cells to the Bacillus proteins induced an inflammatory response, as this might give an indication as to how these bacterial proteins induce the erythema that is a feature of ocular rosacea. ${ }^{4,5}$ The complete elucidation of the role of these proteins in inducing the symptoms of ocular rosacea could open the possibility of developing new therapeutic strategies for the control of this disfiguring condition.

\section{Materials ANd Methods}

\section{Preparation of Bacterial Proteins}

Cultures of B. oleronius were grown at $30^{\circ} \mathrm{C}$ in nutrient broth (Oxoid, Ltd; Thermo Fisher Scientific, Inc., Waltham, MA, USA) under aerobic conditions to stationary phase of growth before protein extractions were performed as described. ${ }^{16}$ This protein fraction was termed "crude B. oleronius protein" and was diluted to a working concentration of $200 \mu \mathrm{g} / \mathrm{mL}$ in PBS ( $\mathrm{pH}$ 7.4). The B. oleronius protein extract was purified by anion exchange separation using fast protein liquid chromatography (FPLC) using an ÄKTA Purifier 100 system (ÄKTA FPLC; GE Healthcare, Little Chalfont, UK) as described. ${ }^{18}$ The "crude B. oleronius protein" extract was incubated at $4{ }^{\circ} \mathrm{C}$ overnight in Q-Sepharose beads (Q Sepharose High Performance; GE Healthcare) and binding buffer (20 $\mathrm{mM}$ piperazine, $10 \mathrm{mM} \mathrm{NaCl}$ in $\mathrm{dH}_{2} \mathrm{O}, \mathrm{pH}$ 4.6). Fractionation by Q-Sepharose charge separation of the crude $B$. oleronius protein extract to the semipurified $B$. oleronius protein preparation was performed by increasing the concentration of a salt gradient using elution buffer ( $20 \mathrm{mM}$ piperazine, $1 \mathrm{M} \mathrm{NaCl}$ in $\mathrm{dH}_{2} \mathrm{O}, \mathrm{pH}$
4.6). The fractions separated from the ÄKTA FPLC column of interest were pooled and precipitated. The semipurified protein preparation was visualized by 1D SDS-PAGE staining with Coomassie blue as a quality assurance of the Q-Sepharose ÄKTA FPLC separation process and maintained at a concentration of $200 \mu \mathrm{g} / \mathrm{mL}$ in PBS (termed as "pure" protein in Figs. 18).

\section{Cell Culture}

Human telomerase-immortalized corneal epithelial cells were maintained in keratinocyte growth medium (KGM)-2 supplemented with KGM-2 SingleQuot Kit Supplements and Growth Factors (Lonza, Basel, Switzerland), in a $5 \% \mathrm{CO}_{2}$ humidified atmosphere incubator at $37^{\circ} \mathrm{C}$, and passaged every 3 to 5 days. Cells were left to adhere overnight before stimulants were added to the media: crude $B$. oleronius protein preparation (2 $\mu \mathrm{g} / \mathrm{mL})$ or semipurified $B$. oleronius protein preparation $(2 \mu \mathrm{g} /$ $\mathrm{mL}$ and $6 \mu \mathrm{g} / \mathrm{mL}$ ).

\section{Corneal Cell Proliferation}

Human telomerase-immortalized corneal epithelial cells were seeded into a 6-well culture plate (Corning Life Sciences, Corning, NY, USA) at a density of $5 \times 10^{5}$ cells per well, allowed to attach, and exposed to semipurified B. oleronius proteins at concentrations of 2 and $6 \mu \mathrm{g} / \mathrm{mL}$. Cell counts were performed on days $0,1,2,3$, and 6 using a hemocytometer (Neubauer improved Hemocytometer; Marienfeld-Superior Ltd., Lauda-Königshofen, Germany) and cell viability was measured using the trypan blue exclusion method. Human telomerase-immortalized corneal epithelial cells were cocultured with the Bacillus proteins for the duration of the assay.

\section{Cell Cycle Analysis}

Human telomerase-immortalized corneal epithelial cells were seeded into 6-well plates (Corning) at a density of $1 \times 10^{4}$ cells per well. Cells attached during a 2-hour incubation and were then treated using KGM-Gold media (Lonza) alone or KGMGold media supplemented with $6 \mu \mathrm{g} / \mathrm{mL}$ "pure" B. oleronius proteins. After 48 hours of exposure, cells were harvested using $0.25 \%$ trypsin/0.022\% EDTA, washed with PBS, and fixed with ice-cold $90 \%$ methanol (Sigma-Aldrich Corp., St. Louis, MO, USA). Samples were stained using propidium iodide (Biotium, Inc., Hayward, CA, USA) according to the manufacturer's instructions and analyzed using a Guava easyCyte HT flow cytometer (Millipore, Billerica, MA, USA). The percentages of cells in Gap-1 $\left(G_{1}\right)$, Synthesis $(S)$, and Gap-2 $\left(G_{2}\right)$ phases of the cell cycle were calculated using the ModFit LT 3.2 DNA cell-cycle analysis software (Verity Software House, Topsham, ME, USA).

\section{Caspase-3 and Caspase-7 Immunofluorescence Assay}

Human telomerase-immortalized corneal epithelial cells were cultured for 3 days in culture dishes (CELLVIEW, cell culture dish with glass bottom, TC, $35 \mathrm{~mm}, 1$ compartment; Greiner Bio-one GMbH, Frickenhausen, Germany) $\left(2 \times 10^{5}\right.$ cells per well) under the following conditions: untreated, dimethyl sulfoxide (DMSO) (1\%, vol/vol), and purified B. oleronius protein $(6 \mu \mathrm{g} / \mathrm{mL})$ before fixing and staining for caspase- $3 / 7$ activity and assessed following the guidelines in the Image-iT LIVE Red Caspase- 3 and -7 Detection Kit (Invitrogen, Dún Laoghaire Co., Dublin, Ireland). Cells were stained with fluorescent-labeled inhibitor of caspases (FLICA) reagent that 


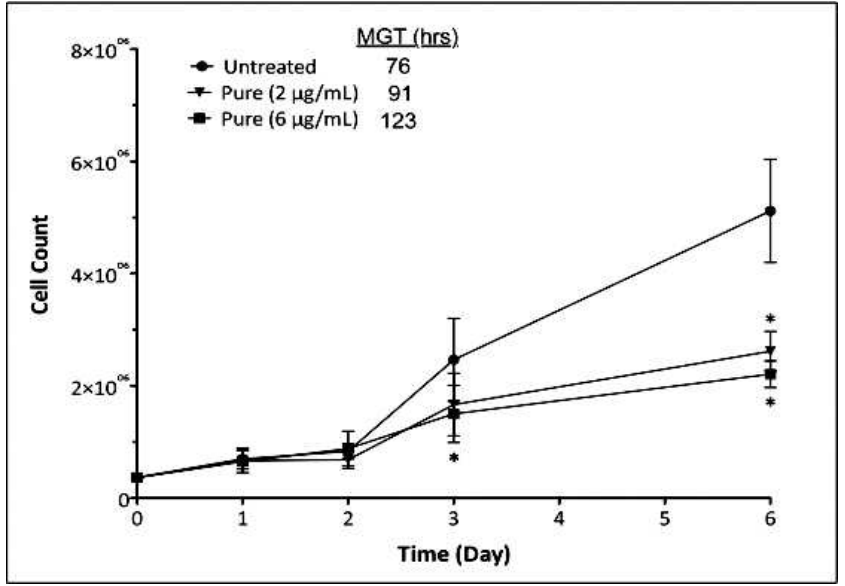

Figure 1. Exposure of B. oleronius proteins reduces the rate of hTCEpi cell proliferation. The MGT for hTCEpi cells during the log phase of growth between day 2 and day 3 of exposure to Bacillus proteins at 2 and $6 \mu \mathrm{g} / \mathrm{mL}$ was calculated to be 91 hours and 123 hours, respectively, compared with 76 hours for untreated cells. The growth of hTCEpi cells was reduced in the presence of B. oleronius in a dosedependent manner. ${ }^{*} P<0.05$.

becomes covalently and irreversibly coupled to active caspase3/7 (excitation/emission at 550/595 nm), and Hoescht 33342 (a nuclear stain with excitation/emission at 350/461 nm) was used to visualize hTCEpi cells positive and negative for caspase$3 / 7$. Results represent experiments performed in triplicate and determined for five fields of view per treatment for each repeat of the assay. Images were captured on a Nikon TiE microscope (Nikon UK Limited, Kinston upon Thames, Surrey, UK) controlled and analyzed using MetaMorph software (Molecular Devices, Marlow, Buckinghamshire, UK).

\section{RNA Extraction and Gene Expression Analysis}

Human telomerase-immortalized corneal epithelial cells $(6 \times$ $10^{4}$ /well) were seeded in 6-well culture dishes and exposed to semipurified $B$. oleronius proteins $(0,2$, or $6 \mu \mathrm{g} / \mathrm{mL})$ for 5 days, with feeding and treatment on alternate days. Following PBS washes $(\times 3)$, tri-reagent $(1 \mathrm{~mL} /$ well $)$ was applied and RNA extracted according to manufacturer's instructions (SigmaAldrich). RNA concentration was determined using a NanoDrop spectrophotometer (ND-1000; Labtech International, East Sussex, England) and cDNA synthesized using a highcapacity RNA to cDNA kit (Applied Biosystems, Carlsbad, CA, USA). Amplification of chemokine ligand-20 (CCL20), IL-1 $\beta$, IL6, IL-8, S100A7, and TNF targets was performed using TaqMan Gene Expression Assays (Hs01011368_m1, Hs01555410_m1, Hs00985639_m1, Hs00174103_m1, Hs00161488_m1, Hs00174128_m1, respectively) in conjunction with an ABI 7500 Fast Real-time PCR thermal cycler (Applied Biosystems, Foster City, CA, USA).

\section{Electrophoresis and Western Blots}

Cell supernatants were collected from hTCEpi cells exposed to semipurified B. oleronius protein ( 2 and $6 \mu \mathrm{g} / \mathrm{mL}$ ) for 24,48 , or 72 hours in culture conditions described above. Collected samples were concentrated by centrifugation using 3000 MCWO Vivaspin-20 (Vivaproducts, Littleton, MA, USA) filter columns, and protein $(20 \mu \mathrm{g})$ was loaded onto a $10 \%$ acrylamide gel and separated under reducing conditions. After electrophoresis, resolved proteins were transferred onto a nitrocellulose membrane (Fisher Scientific, Ballycoolin, Dublin,
Ireland), using a transfer rig in transfer buffer ( $25 \mathrm{mM}$ Tris, 192 $\mathrm{mM}$ glycine, methanol [20\%, vol/vol] in $\left.\mathrm{dH}_{2} \mathrm{O}, \mathrm{pH} 8.3\right)$.

Membranes were blocked using $1 \%(\mathrm{wt} / \mathrm{vol}) \mathrm{BSA}$ in Trisbuffered saline (TBS) ( $\mathrm{pH} 7.6$ ) with $0.05 \%$ (vol/vol) Tween-20 (Sigma-Aldrich) for 1 hour at room temperature. Primary antibodies were diluted as follows: anti-CCL20 (raised in rabbit [Abnova, Taipei City, Taiwan]) 1/500; anti-S100A7 (raised in rabbit [Sigma-Aldrich]) 1/600; anti-MMP-9 (raised in rabbit [Sigma-Aldrich]) 1/500; and incubated at $4^{\circ} \mathrm{C}$ overnight.

An anti-human horseradish peroxidase (HRP)-linked secondary antibody (HRP-linked rabbit antisera at a dilution of 1/ 1000) was applied and incubated at room temperature for 2 hours. Immunoreactive protein bands were visualized by incubating the membranes for 10 minutes in $10 \mathrm{mg}$ diaminobenzidine tetrahydrochloride in $15 \mathrm{~mL}$ of $100 \mathrm{mmol} / \mathrm{L}$ Tris- $\mathrm{HCl}$ ( $\mathrm{pH}$ 7.6) containing $15 \mu \mathrm{L}$ hydrogen peroxide (Sigma-Aldrich) before washing in distilled water and drying. Immuno-bands were quantified by densitometry using ImageJ software (http:// imagej.nih.gov/ij/; provided in the public domain by the National Institutes of Health, Bethesda, MD, USA).

\section{Enzyme-Linked Immunosorbent Assay}

Human telomerase-immortalized corneal epithelial cells were exposed to crude $B$. oleronius protein $(2 \mu \mathrm{g} / \mathrm{mL})$, or semipurified B. oleronius protein $(2 \mu \mathrm{g} / \mathrm{mL})$ for 24 hours or 72 hours and the supernatants were collected. Secretion levels of IL- 6 and IL-8 were measured using commercial ELISA kits (minidevelopment ELISA kit; PeproTech, Rocky Hill, NJ, USA) according to the manufacturer's guidelines.

\section{Gelatinase Zymograms for MMP-9 Activity}

Cell supernatants collected from cell proliferation assays at days 3 and 6 after exposure of hTCEpi cells to B. oleronius semipurified protein extract at 2 and $6 \mu \mathrm{g} / \mathrm{mL}$ were concentrated by centrifugation using 3000 MCWO Vivaspin-20 (Vivaproducts) filter columns and loaded onto Novex $10 \%$ zymogram (gelatin) gels (Invitrogen). Following electrophoresis, gels were incubated in zymogram-renaturing buffer (Invitrogen) for 30 minutes at room temperature, left at $37^{\circ} \mathrm{C}$ overnight in developing buffer (Invitrogen), and stained with Colloidal Coomassie (Brilliant Blue G-Colloidal Concentrate, Electrophoresis Reagent; Sigma-Aldrich) for 2 hours before destaining of gels in distilled water and recording of gel images.

\section{Statistical Methods}

Resultant cycle threshold (Ct) values from real-time PCR expression analyses, were normalized against human glyceraldehyde 3-phosphate dehydrogenase endogenous control expression (Hs99999905_m1) and changes in expression calculated using the relative quantification $(\mathrm{RQ})=2-\Delta \Delta \mathrm{Ct}$ equation. All experiments were performed on three independent occasions and results are presented as the mean $\pm \mathrm{SE}$. Statistical significance was assessed by the Student's $t$-test using GraphPad Prism version 5.00 for Mac OS X (GraphPad Software, San Diego, CA, USA; www.graphpad.com). $P$ values less than $0.05\left(^{*}\right)$, less than $0.01\left(^{* *}\right)$, or less than $0.001\left(^{(* * *)}\right.$ were deemed statistically significant.

\section{Results}

\section{Effect of Bacillus Proteins on hTCEpi Cell Proliferation}

Exposure of hTCEpi cells to 2 or $6 \mu \mathrm{g} / \mathrm{mL}$ Bacillus protein reduced the growth rate of cells over a 6-day period (Fig. 1). Cell proliferation was reduced by $34 \%$ and $42 \%$ in those cultures that 


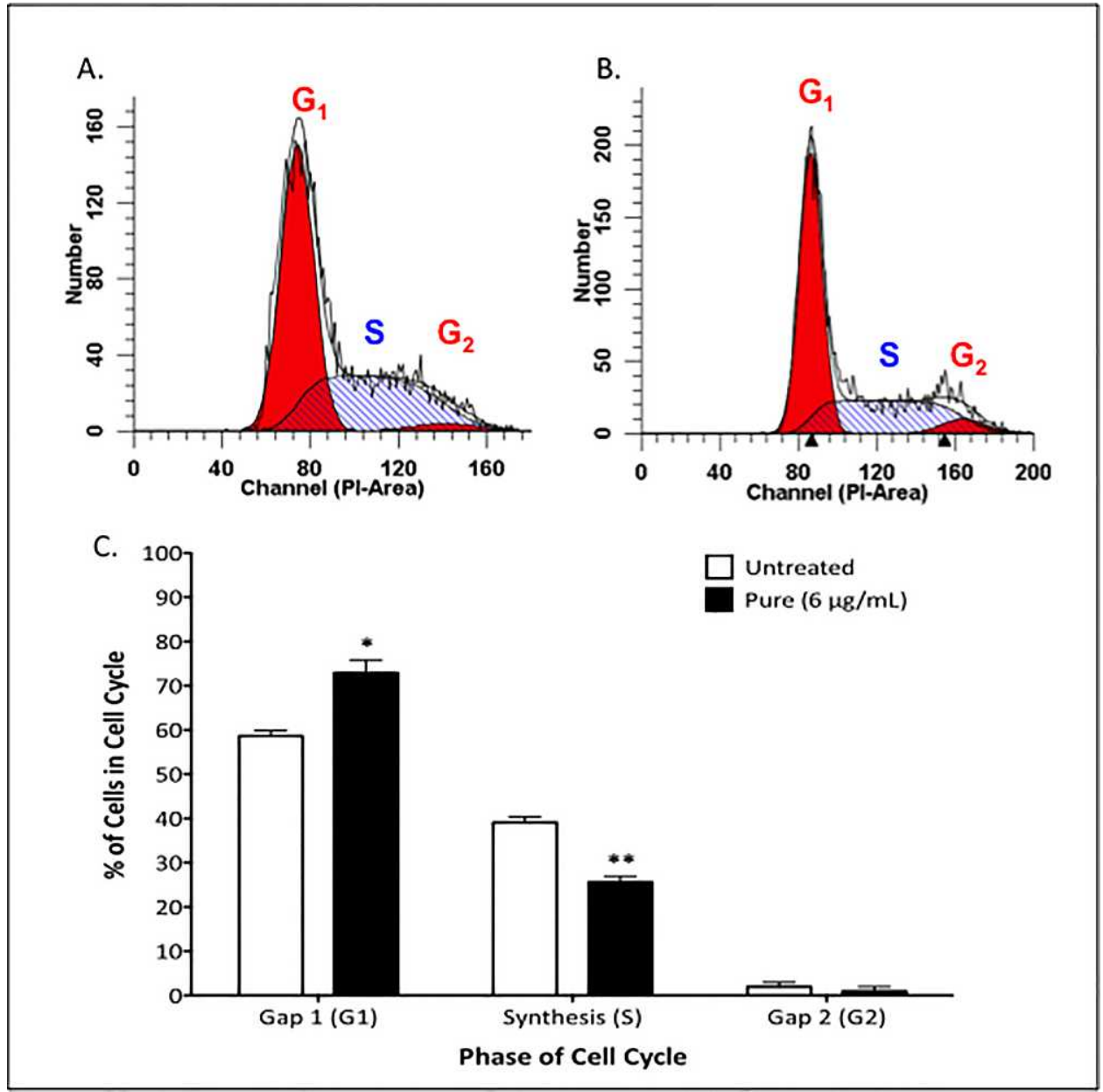

FIGURE 2. Effect of B. oleronius protein on hTCEpi cell cycle. Cell cycle characteristics of both untreated (A) and semipurified B. oleronius protein $(6 \mu \mathrm{g} / \mathrm{mL})$-treated (B) hTCEpi cells were assessed by DNA content analysis after 48 hours of incubation. B. oleronius semipurified protein-treated cells demonstrate an increased proportion of cells in $G_{1}$ phase and a decreased proportion of cells in the $S$ phase relative to untreated controls $(C)$ indicating that exposure to semipurified B. oleronius protein inhibits transition from the $\mathrm{G}_{1}$ growth phase into the $\mathrm{S}$ phase. ${ }^{*} P<0.05$, ${ }^{* * *} P<0.001$.

were exposed to 2 and $6 \mu \mathrm{g} / \mathrm{mL}$ semipurified Bacillus protein, respectively, compared with the total cell number in the untreated controls after a 72 -hour incubation period. The mean generation time (MGT) for cells during the log phase of growth between day 2 and day 3 of exposure to Bacillus proteins at 2 and $6 \mu \mathrm{g} / \mathrm{mL}$ was calculated to be 91 hours and 123 hours, respectively, whereas it was 76 hours in the control. A significant decrease in corneal epithelial cell growth was observed at day 3 following exposure to semipurified Bacillus protein $(6 \mu \mathrm{g} / \mathrm{mL})(P=0.0185)$ and reduced growth of hTCEpi cells following 6 days of exposure to 2 or $6 \mu \mathrm{g} / \mathrm{mL}$ semipurified Bacillus protein relative to control hTCEpi cells was significant ( $P=0.0111$ and $P=0.0133$, respectively). During the course of a 6-day exposure to the semipurified Bacillus protein at 2 and 6 $\mu \mathrm{g} / \mathrm{mL}$, a statistical difference in total cell number between the two doses at each time point was not observed, but a dosedependent increase in the MGT at day 3 between the semipurified Bacillus protein treatments at 2 and $6 \mu \mathrm{g} / \mathrm{mL}$ was found to be statistically significant $(P=0.0427)$.

\section{Effect of B. oleronius Protein Exposure on Cell Cycle}

Cell-cycle analysis was performed to determine the effect of semipurified $B$. oleronius proteins $(6 \mu \mathrm{g} / \mathrm{mL})$ on hTCEpi progression through the phases of the cell cycle. By comparing the DNA content of untreated hTCEpi cells (Fig. 2A) and $B$. oleronius protein-treated hTCEpi cells (Fig. 2B), it was observed that exposure to $B$. oleronius proteins induced significant $G_{1}$ phase arrest $(P=0.0015)$ by increasing the percentage of hTCEpi cells in the $G_{1}$ phase from $58.66 \%$ to $72.91 \%$ (Fig. 2C). Accordingly, the percentage of cells in the $S$ phase also decreased (from $39.13 \%$ to $25.61 \%$ ), concurrent with $B$. oleronius protein treatment $(P=0.002)$ (Fig. $2 \mathrm{C})$, suggesting that $B$. oleronius protein exposure may reduce hTCEpi proliferation by impeding progression from the $G_{1}$ growth phase to the $S$ (synthesis) phase of the cell cycle.

\section{Exposure to Bacillus Proteins Does Not Induce Apoptosis in hTCEpi Cells}

The cleavage of caspases, a family of cysteine-aspartic acidspecific proteases, represent a distinctive feature of early apoptosis. The exposure of hTCEpi cells to $6 \mu \mathrm{g} / \mathrm{mL}$ semipurified $B$. oleronius protein did not induce the increased production of caspase-3 and -7. After a 72-hour treatment period, the semipurified Bacillus protein preparation showed that $3.09 \%$ of corneal cells were positive for the apoptotic markers caspase- 3 and -7 , compared with $3.16 \%$ of control cells. In contrast, $61.34 \%$ of corneal cells exposed to DMSO (1\%, vol/vol) were positive for these markers $(P<0.0001)$ (Fig. 3). The noninduction of caspases 


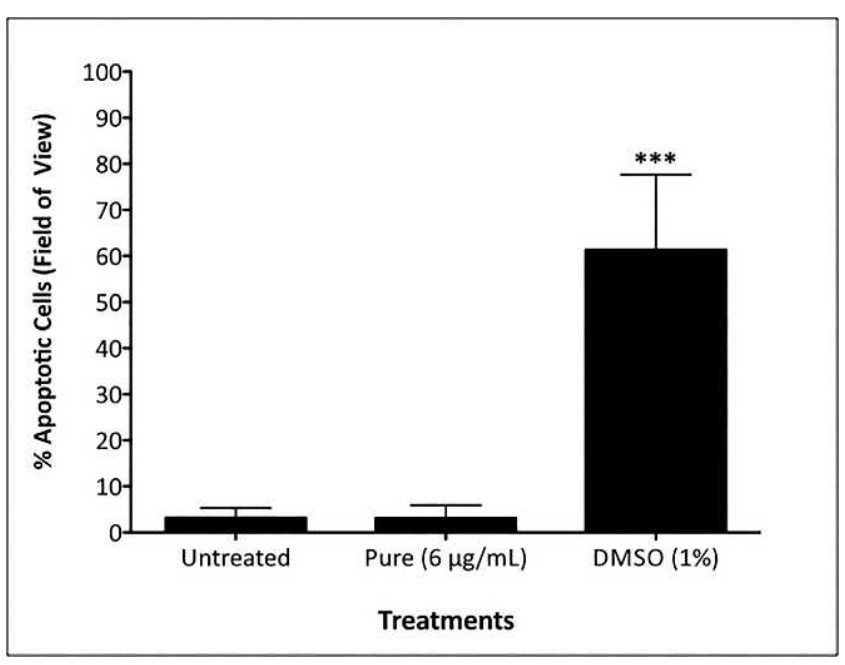

Figure 3. The hTCEpi cells exposed to $B$. oleronius protein preparation do not exhibit caspase activation. The hTCEpi cells were exposed to semipurified Bacillus proteins $(6 \mu \mathrm{g} / \mathrm{mL})$, DMSO (1\%, vol/ vol), or untreated (PBS) for 3 days. Caspase- 3 and -7 activity was assessed by capturing immunofluorescence images followed by analysis through MetaMorph software. Results represent experiments performed in triplicate and determined using five fields of view per treatment for each repeat of the assay. ${ }^{* * *} P<0.0001$.

after exposure to semipurified B. oleronius protein preparation suggests that the effect on growth of hTCEpi cells is antiproliferative rather than via the induction of apoptosis.

\section{Gene Expression Changes Induced by $B$. oleronius Antigen Exposure}

To assess the effect of $B$. oleronius protein exposure on hTCEpi gene expression, the expression of a number of genes that are known to participate in proinflammatory, immune-modulated, and defense-associated activities during wound healing was assessed (Fig. 4). Immediately after barrier disruption in a healthy wound, proinflammatory cytokines, including IL-6, IL-8, IL-1 $\beta$, and TNF, are released. (4) These cytokines function in the acute phase to stimulate inflammation and attract immune cells to the site of injury; however, if proinflammatory cytokines continue to be secreted at elevated concentrations after the acute phase, complications may result. The hTCEpi cells exposed to both low $(2 \mu \mathrm{g} / \mathrm{mL})$ and high $(6 \mu \mathrm{g} / \mathrm{mL})$ concentrations of $B$. oleronius protein resulted in significant overexpression of proinflammatory cytokines IL-1 $\beta$ (3.6-fold, $P=0.0027$, and 3.0-fold, $P=0.0083$, respectively) and TNF (4.9-fold, $P=$ 0.0019 , and 5.1-fold, $P=0.0014$, respectively) relative to untreated cells (Fig. 4). Interleukins are regulators of the corneal response to injury, and IL-1 $\beta$ acts as a proinflammatory mediator, stimulating stromal fibroblasts to secrete chemokines and amplify inflammatory responses, ${ }^{22}$ whereas TNF also plays important roles in corneal inflammation and wound healing. ${ }^{23}$ The highest relative upregulation of cytokine expressions assessed were those of IL-6 (11.6-fold, $P=0.0337)$ and IL-8 (7.8-fold, $P=0.0378)$ after exposure of cells to $6 \mu \mathrm{g} / \mathrm{mL}$ B. oleronius. Secreted IL-6 is known to be elevated in chronic wounds and overproduction of IL-6 protein may lead to the development of autoimmune inflammatory diseases. ${ }^{24,25}$ Elevated IL-8 has been observed in wounds that display retarded healing and IL-8 may directly contribute to this effect by inhibition of keratinocyte replication. ${ }^{26}$ In the cornea, IL-8 overexpression also has

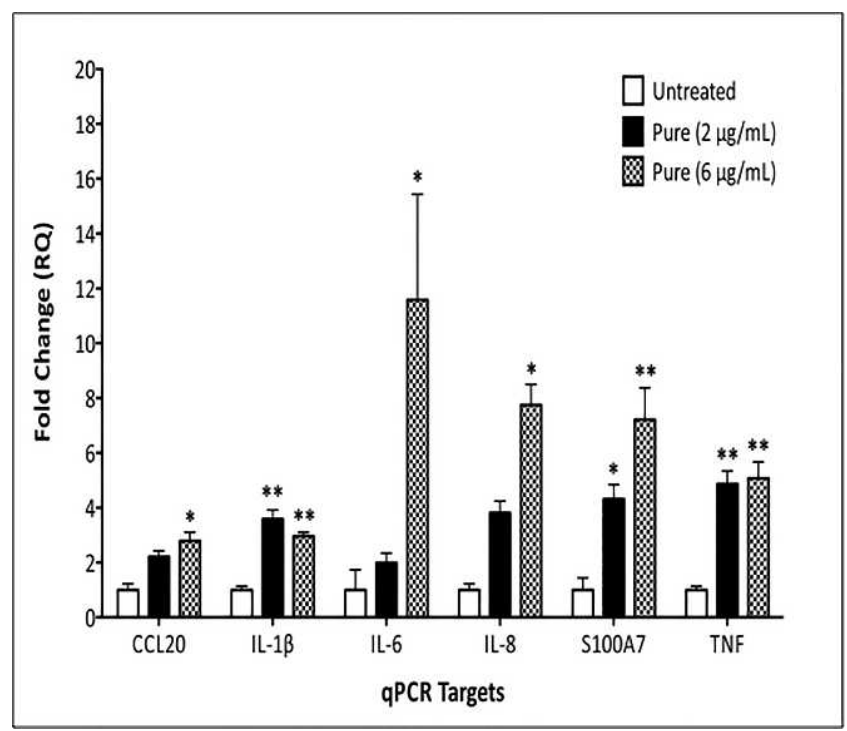

Figure 4. Effect of $B$. oleronius protein extract on gene expression in hTCEpi cells. The effect of semipurified $B$. oleronius protein exposure on wound-associated gene expression was assessed by quantitative RTPCR. ${ }^{*} P<0.05,{ }^{* *} P<0.001$.

been associated with ulcer formation via chemoattraction of macrophages and subsequent destruction of tissue. ${ }^{27} \mathrm{Al}-$ though not itself a cytokine, overexpression of CCL20 (2.8fold, $P=0.0355$ ) also was observed in cells exposed to $B$. oleronius antigen $(6 \mu \mathrm{g} / \mathrm{mL})$. Chemokine ligand-20 affects corneal wound healing indirectly by attraction of specialized IL-22-secreting $\gamma \delta \mathrm{T}$ cells, which induce an inflammatory response. ${ }^{28}$ The antimicrobial peptide Psoriasin-coding gene S100A7 displayed overexpression at both $2 \mu \mathrm{g} / \mathrm{mL}$ and $6 \mu \mathrm{g} /$ $\mathrm{mL}$ B. oleronius exposure (4.3-fold, $P=0.0124$, and 5.1-fold, $P=0.0022$, respectively). This protein was first discovered due to its oversecretion in inflammatory skin disease psoriasis and is known to be present at the ocular surface in both tear films and corneal epithelium; however, associations with corneal disease are as yet undescribed. ${ }^{29}$

\section{Effect of Bacillus Proteins on Expression of CCL20 and S100A7 in Cells}

Human telomerase-immortalized corneal epithelial cells were exposed to semipurified B. oleronius proteins $(2 \mu \mathrm{g} / \mathrm{mL}$ and 6 $\mu \mathrm{g} / \mathrm{mL}$ ) for 24,48 , and 72 hours, as described, and Western blots were performed to assess the effect on the expression of the defensins, CCL20 and S100A7 (Figs. 5A, 5C, respectively). The results revealed increased expression of CCL20 in corneal cells exposed to semipurified B. oleronius proteins at $2 \mu \mathrm{g} / \mathrm{mL}$ and $6 \mu \mathrm{g} / \mathrm{mL}$, with a $2.1(P=0.0323)$ and 2.9 -fold increase, respectively, relative to the control at 24 hours. An increase of CCL20 expression was observed at 48 hours, with a $2.6(P=$ $0.0057)$ and 3.9-fold $(P=0.0178)$ increase of CCL20 expression after exposure to the $2 \mu \mathrm{g} / \mathrm{mL}$ and $6 \mu \mathrm{g} / \mathrm{mL}$ semipurified $B$. oleronius protein preparations, respectively. At 72 hours, CCL20 expression in corneal cells treated with $2 \mu \mathrm{g} / \mathrm{mL}$ and 6 $\mu \mathrm{g} / \mathrm{mL}$ semipurified Bacillus proteins showed a 2.5 -fold $(P=$ $0.0024)$ and 4.1-fold $(P=0.0129)$ increase, respectively, compared with the control. A significant dose-dependent response between the $2-\mu \mathrm{g} / \mathrm{mL}$ and $6-\mu \mathrm{g} / \mathrm{mL}$ semipurified Bacillus protein concentrations for the expression of CCL20 was not observed at 24,48 , or 72 hours after stimulation (Fig. 5B). Similarly, an increase in the expression of S100A7 was observed in hTCEpi cells exposed to semipurified B. oleronius 
A.

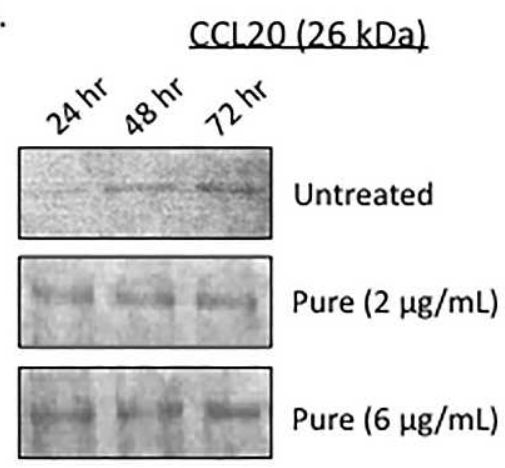

C.

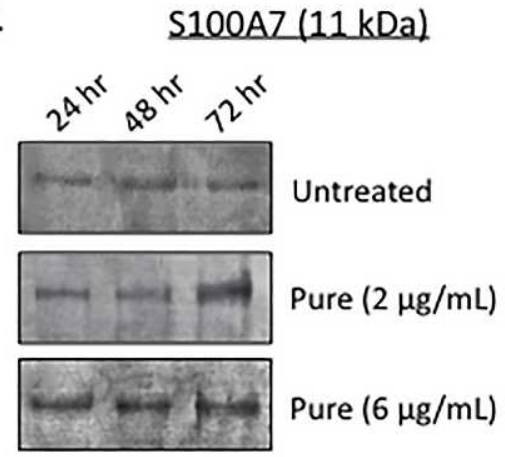

B.

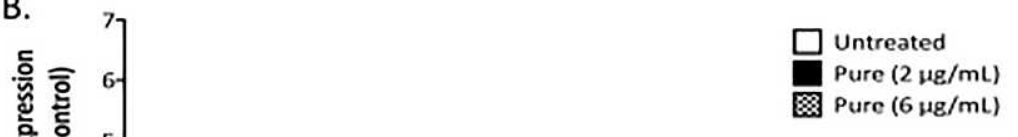

D.

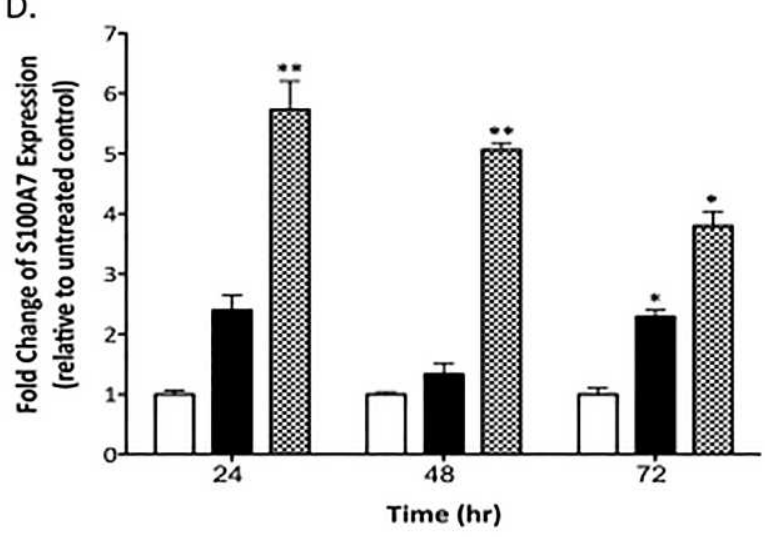

FIGURE 5. Effect of B. oleronius protein preparation on CCL20 and S100A7 expression in hTCEpi cells. The expression of CCL20 and S100A7 by hTCEpi cells following exposure to semipurified B. oleronius proteins (pure 2 and $6 \mu \mathrm{g} / \mathrm{mL}$ ) was assessed by Western blot at 24,48 , and 72 hours after stimulation $(\mathbf{A}, \mathbf{C})$, and the expression of CCL20 and S100A7 was assessed by densitometric analysis $(\mathbf{B}, \mathbf{D}) .{ }^{*} P<0.05,{ }^{* *} P<0.001$.

proteins $(2$ and $6 \mu \mathrm{g} / \mathrm{mL})$. At 24 hours, a 2.4 - and 5.7 -fold $(P=$ $0.005)$ increase in expression of S100A7 compared with the untreated control was recorded. At 48 hours, the $6-\mu \mathrm{g} / \mathrm{mL}$ dose of semipurified $B$. oleronius protein extract induced a 5.1 -fold increase in the expression of $\mathrm{S} 100 \mathrm{~A} 7(P=0.0012)$. An increase of S100A7 expression was evident at 72 hours after exposure to the $2-\mu \mathrm{g} / \mathrm{mL}$ and $6-\mu \mathrm{g} / \mathrm{mL}$ semipurified Bacillus protein preparations with a 2.3 -fold $(P=0.0163)$ and 3.8 -fold $(P=$ 0.0103 ) increase observed for each dose, respectively. A significant dose-dependent difference between the $2-\mu \mathrm{g} / \mathrm{mL}$ and $6-\mu \mathrm{g} / \mathrm{mL}$ semipurified Bacillus protein treatments for the expression of S100A7 was recorded after $24-(P=0.0005)$, 48$(P<0.0001)$, and 72 -hour $(P=0.0002)$ exposure of corneal cells (Fig. 5D).

\section{Cytokine Production in hTCEpi Cells Following Exposure to Bacillus Proteins}

Analysis of the production of cytokines by hTCEpi cells exposed to crude and semipurified $B$. oleronius proteins (2 $\mu \mathrm{g} / \mathrm{mL}$ ) for 24 and 72 hours revealed increased production of IL-6 and IL-8 (Figs. 6A, 6B) but not of IL-1 $\beta$ and TNF- $\alpha$ (data not presented). There was a statistically significant increase in the secretion of IL-6 in cells exposed to semipurified $B$. oleronius protein preparation at 24 and 72 hours $(P<0.0001$ and $P=0.0014$, respectively). A significant increase in IL-6 secretion also was observed in cells exposed to crude $B$. oleronius protein preparation at 24 hours $(P=0.0255)$. The increased production of IL-6 after exposure of the hTCEpi cells to the semipurified $B$. oleronius protein $(2 \mu \mathrm{g} / \mathrm{mL})$ compared with the crude $B$. oleronius protein $(2 \mu \mathrm{g} / \mathrm{mL})$ was statistically significant at 24 hours $(P=0.0034)$ but not at 72 hours (Fig. 6A). Interleukin8 secretion reached the highest level in cells exposed to crude Bacillus protein preparation at 24 hours $(230 \mathrm{pg} / \mathrm{mL})$ $(P=0.0003)$. Semipurified $B$. oleronius protein preparation also stimulated IL-8 secretion at 24 and 72 hours. The secretion of IL-8 by corneal cells stimulated by crude $B$. oleronius protein preparation $(2 \mu \mathrm{g} / \mathrm{mL})$ compared with that by corneal cells stimulated by pure $B$. oleronius protein $(2$ $\mu \mathrm{g} / \mathrm{mL})$ at 24 hours was statistically significant $(P=0.0485)$. At 72 hours of exposure, secretion of IL-8 by cells exposed to the semipurified $B$. oleronius protein was deemed to be significant $(P=0.0003)$ compared with that by cells exposed to the crude B. oleronius protein (Fig. 6B).

\section{Effect of Bacillus Proteins on Expression of MMP-9 hTCEpi in Cells}

Human telomerase-immortalized corneal epithelial cells were exposed to semipurified B. oleronius proteins $(2 \mu \mathrm{g} / \mathrm{mL}$ and 6 $\mu \mathrm{g} / \mathrm{mL}$ ) for 24,48 , and 72 hours. Cell culture supernatants were collected, filter-concentrated, and resolved as described, and Western blots were performed to assess the effect of Bacillus proteins on the expression of MMP-9. The results revealed increased expression of MMP-9 in corneal cells exposed to semipurified $B$. oleronius proteins at $2 \mu \mathrm{g} / \mathrm{mL}$ and $6 \mu \mathrm{g} / \mathrm{mL}$, with a 2.2 -fold $(P<0.0001)$ and 3.5 -fold $(P=$ 


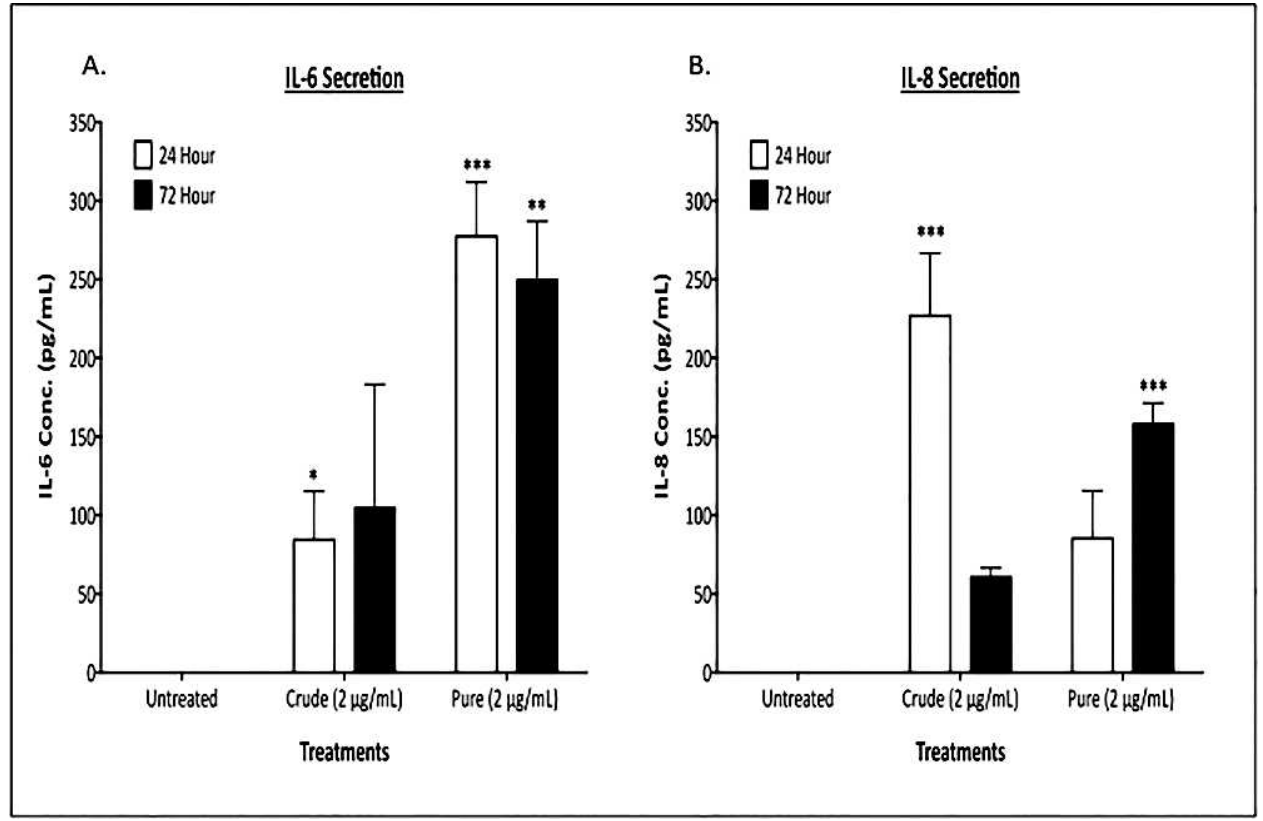

Figure 6. Interleukin-6 and IL-8 secretion by hTCEpi cells exposed to B. oleronius protein preparation. Interleukin-6 and IL-8 secreted by hTCEpi cells in response to crude (crude $2 \mu \mathrm{g} / \mathrm{mL}$ ) and semipurified Bacillus (pure $2 \mu \mathrm{g} / \mathrm{mL}$ ) protein preparations were assessed 24 hours and 72 hours after stimulation by ELISA analysis $(\mathbf{A}, \mathbf{B}) .{ }^{*} P<0.05,{ }^{* *} P<0.01,{ }^{* * *} P<0.001$.

0.0096) increase, respectively, relative to the control at 24 hours. A 1.5-fold $(P=0.0355)$ and 3.2-fold $(P=0.003)$ increase of MMP-9 expression was observed at 48 hours, after exposure to the 2- and $6-\mu \mathrm{g} / \mathrm{mL}$ semipurified $B$. oleronius protein preparations, respectively. At 72 hours, MMP-9 expression in corneal cells treated with 2 - and $6-\mu \mathrm{g} / \mathrm{mL}$ semipurified Bacillus proteins showed a 1.3- and 2.2-fold increase, respectively, compared with the control. A significant dose-dependent

A.
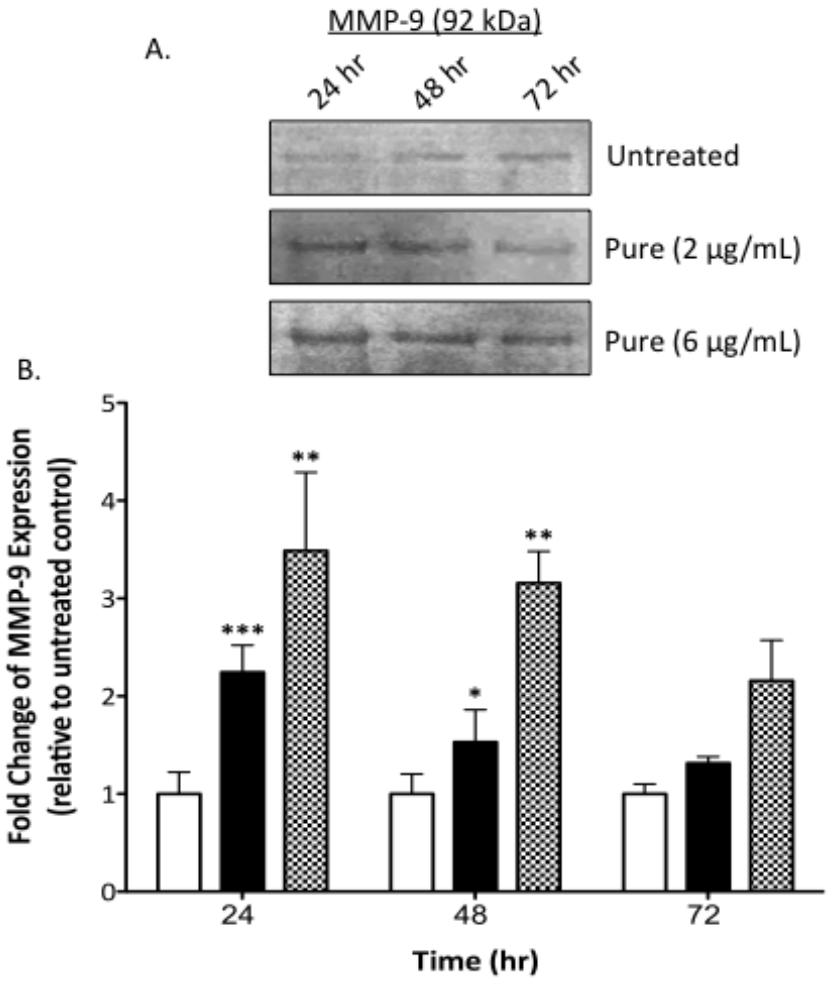

Untreated

Pure $(2 \mu \mathrm{g} / \mathrm{mL})$

Pure $(6 \mu \mathrm{g} / \mathrm{mL})$

FiguRE 7. Matrix metalloproteinase-9 expression in hTCEpi cells exposed to B. oleronius protein preparation. The expression of MMP-9 in supernatants of hTCEpi cells exposed to semipurified B. oleronius protein preparations $(2$ and $6 \mu \mathrm{g} / \mathrm{mL})$ was analyzed through Western blotting 24 , 48, and 72 hours after stimulation (A), and MMP-9 expression was assessed by densitometric analysis $(\mathbf{B})$. ${ }^{*} P<0.05,{ }^{* *} P<0.01,{ }^{* * *} P<0.001$. 


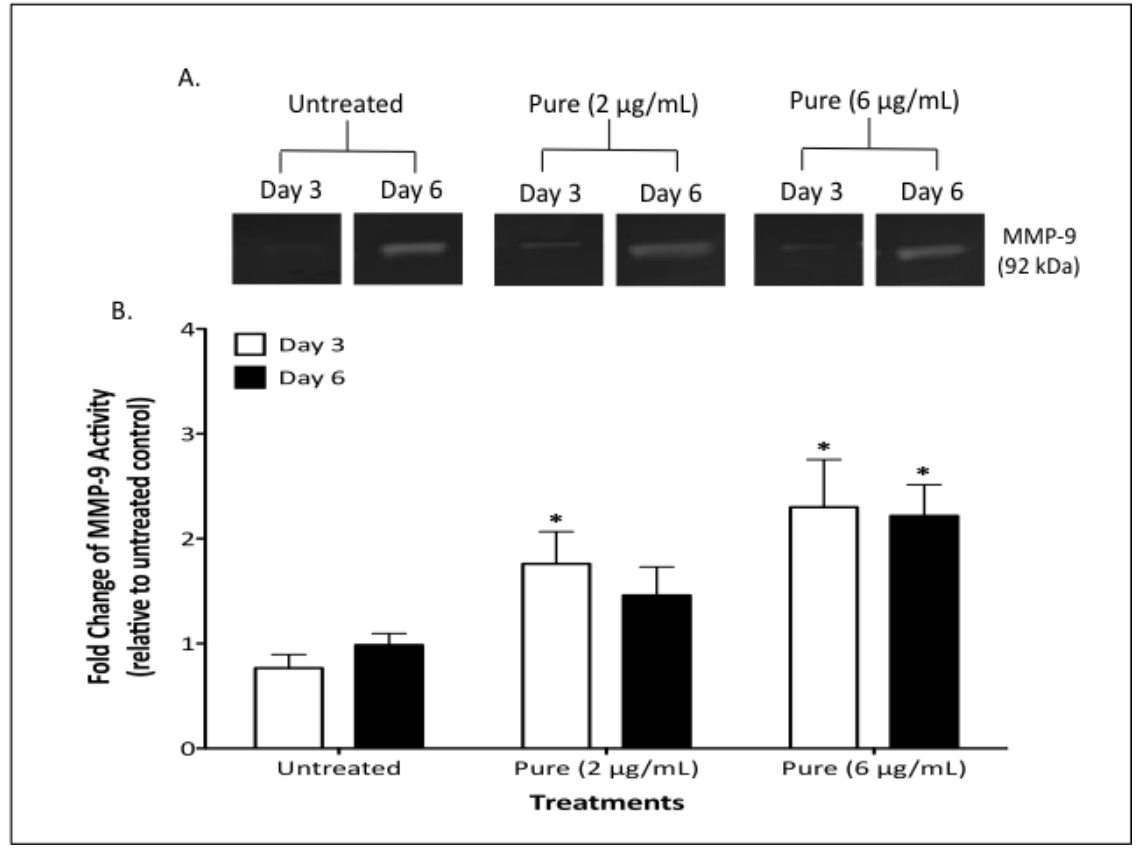

FIGURE 8. Matrix metalloproteinase-9 activity in hTCEpi cells exposed to B. oleronius protein preparation. Increased enzymatic activity of MMP-9 in hTCEpi cells exposed to semipurified B. oleronius proteins ( 2 and $6 \mu \mathrm{g} / \mathrm{mL}), 3$ days and 6 days after stimulation was observed compared with the untreated control (A). Densitometry was calculated using ImageJ software and images from corresponding zymograms show that activity of MMP-9 increases after stimulation of hTCEpi cells to the B. oleronius protein extracts, and a significant increase of MMP-9 activity was recorded at day 6 after exposure to the higher concentration of protein $(6 \mu \mathrm{g} / \mathrm{mL})(P=0.0186)(\mathbf{B}) .{ }^{*} P<0.05$.

change in expression of MMP-9 between the $2 \mu \mathrm{g} / \mathrm{mL}$ and $6 \mu \mathrm{g} /$ $\mathrm{mL}$ semipurified Bacillus protein treatments was not observed at 24 or 72 hours, but a significant difference in dose-response was recorded at 48 hours $(P=0.0105)$ (Fig. 7).

\section{Exposure of Cells to Bacillus Proteins Induces Increased MMP-9 Activity}

Human telomerase-immortalized corneal epithelial cells were exposed to 2- or $6-\mu \mathrm{g} / \mathrm{mL}$ Bacillus protein preparations for up to 6 days, and MMP-9 activity was measured as described. The results revealed a significant dose-dependent increase in MMP9 activity over the course of the experiment and a 1.8 -fold $(P=$ $0.0134)$ and 2.3 -fold $(P=0.0215)$ increase in MMP-9 activity was shown after stimulation of hTCEpi cells with 2- and $6-\mu \mathrm{g} /$ $\mathrm{mL}$ semipurified $B$. oleronius protein after 3 days of exposure. At day 6, a 1.5-fold increase in MMP-9 activity was recorded after exposure of hTCEpi cells to the semipurified B. oleronius protein $(2 \mu \mathrm{g} / \mathrm{mL})$, and a statistically significant increase in MMP-9 activity was observed in cells exposed to the higher dose of semipurified $B$. oleronius protein extract $(6 \mu \mathrm{g} / \mathrm{mL})(P$ $=0.0186$ ); a 2.2-fold increase was observed at day 6 compared with untreated hTCEpi cells (Fig. 8). Matrix metalloproteinase9 plays a role in tissue degradation, but is also a trigger for neovascularization in vivo. The growth of new blood vessels is a feature of corneal damage in ocular rosacea. ${ }^{5,6}$

\section{Discussion}

The results presented here demonstrate that exposure of a corneal epithelial cell line to Bacillus proteins results in a reduction in cell proliferation and the induction of an inflammatory response as indicated by the increased expression of genes coding for IL-6, IL-1 $\beta$, IL-8, S100A7, and TNF- $\alpha$, and elevated MMP-9 production and activity. A dose-response effect was observed when hTCEpi cells were exposed to different concentrations of Bacillus protein (i.e., $2 \mu \mathrm{g} / \mathrm{mL}$ and $6 \mu \mathrm{g} / \mathrm{mL}$ ), and this effect is particularly evident in changes in cell proliferation (MGT at day 3; $P=0.0427$ ) (Fig. 1), S100A7 expression (at $24[P=0.0005], 48[P<0.0001]$, and 72 hours $[P=0.0002]$ ) (Figs. 5C, 5D), and MMP-9 expression (at 48 hours; $P=0.0105$ ) (Fig. 7). Corneal damage is one of the features of ocular rosacea and leads to the degradation of the corneal surface and the formation of sterile ulcers and corneal scaring. ${ }^{5,6}$ We previously demonstrated the ability of Bacillus proteins to induce an aberrant wound-healing response in cultured hTCEpi cells. ${ }^{21}$

Exposure of hTCEpi cells to the Bacillus protein preparation reduced the rate of proliferation and the antiproliferative effect was demonstrated to be due to $G_{1}$ phase arrest. Exposure to the Bacillus proteins did not induce apoptosis, consequently the reduction in cell proliferation was not due to increased levels of cell death. The elevated expression of the cytokines IL-1 $\beta$, IL- 6 , IL-8, and TNF- $\alpha$ has been shown in a number of inflammatory cornea pathologies. ${ }^{30,31}$ The elevation of these cytokines results in angiogenesis, inflammation, and sterile ulcer formation due to their upregulation of MMP-9. ${ }^{31-33}$ However, a recent study demonstrated no increase in these cytokines in the tear fluid of rosacea patients and an upregulation of these cytokines in ocular rosacea patients was not observed. ${ }^{34}$ The lack of expression may be due to the ocular rosacea patients possessing only mild symptoms and thus alterations in expression were too low to be detected. Chemokine ligand-20/MIP-3 $\alpha$ is similar functionally to the $\beta$ defensins in its role as an antibacterial agent and the recruitment of cells into the cornea after wounding. ${ }^{35-37}$ It has been shown to be upregulated by the cytokines IL-1 $\beta$ and TNF- $\alpha$ in cornea. ${ }^{38}$

The exposure of hTCEpi cells to Bacillus proteins induced the increased expression and activity of MMP-9. Matrix metalloproteinase- 9 is expressed during cell migration and matrix remodeling in cornea wound repair by the cornea 
epithelium. ${ }^{39}$ It also controls timing of inflammation response around cornea repair. ${ }^{40}$ However, its expression is finely balanced and elevated levels of MMP-9 have been demonstrated to have a negative role in epithelial cell replication and barrier function in the cornea. ${ }^{41}$ In this context, elevation of MMP-9 has been linked to a number of corneal pathologies, including sterile ulcer formation and ocular rosacea. ${ }^{42-44}$ The results presented here show the effect of Bacillus proteins on transformed corneal cells over a short time frame and demonstrate that the increased expression and activity of MMP-9 corresponds with an increased mean generation time and decreased corneal cell proliferation at day 3 , a $G_{1} / S$ transition block in the cell cycle at day 2 , increased expression of S100A7 and CCL20/MIP-3 $\alpha$, and increased production of IL-6 and IL-8.

Elevated densities of Demodex mites on the eyelashes are a feature of ocular rosacea, ${ }^{5,6}$ but their role in the etiology of the condition is unclear. ${ }^{7,10,11}$ We have previously demonstrated a positive correlation between serum reactivity to Bacillus proteins and ocular rosacea, thus suggesting a role for this bacterium in the condition. ${ }^{12}$ One possible scenario linking the elevated density of Demodex mites and the induction of corneal damage involves the release of bacterial cells/antigens from dead Demodex mites on the eyelashes. These may fall onto the corneal surface and induce an aberrant wound-healing response. ${ }^{21}$ In addition, the results presented here indicate the induction of an inflammatory response that would contribute to the degradation of corneal tissue and the induction of sterile ulcers or scarring in vivo. Understanding the interaction of Demodex-associated Bacillus proteins with the corneal surface may aid in the design of specific therapies to reduce the severity of symptoms arising from this interaction.

\section{Acknowledgments}

Supported by the Higher Education Authority of Ireland under PRTLI5 and is being cofunded by the Irish government and the EU under Ireland's Structural Funds Programme 2007-2013: Investing in your future. This research was partially funded by the $3 \mathrm{U}$ Biomedical Research program (Dublin City University-National University of Ireland Maynooth-Royal College of Surgeons in Ireland).

Disclosure: F.W. McMahon, None; C. Gallagher, None; N. O'Reilly, None; M. Clynes, None; F. O'Sullivan, None; K. Kavanagh, None

\section{References}

1. Powell FC. Rosacea. $N$ Engl J Med. 2005;352:793-803.

2. Gupta AK, Chaudhry MM. Rosacea and its management: an overview. J Eur Acad Dermatol Venereol. 2005;19:273-285.

3. Wilkin J, Dahl M, Detmar M, et al. Standard classification of rosacea: report of the National Rosacea Society Expert Committee on the Classification and Staging of Rosacea. $J$ Am Acad Dermatol. 2002;46:584-587.

4. Jenkins MS, Brown SI, Lempert SL, Weinberg RJ. Ocular rosacea. Am J Ophthalmol. 1979;88:618-622.

5. Oltz M, Check J. Rosacea and its ocular manifestations. Optometry. 2011;82:92-103.

6. Kheirkhah A, Casas V, Li W, Raju VK, Tseng SCG. Corneal manifestations of ocular Demodex infestation. Am J Ophthalmol. 2007;143:743-749.

7. Yamasaki K, Gallo RL. The molecular pathology of rosacea. $J$ Dermatol Sci. 2009;55:77-81.

8. Bonner E, Eustace P, Powell FC. The Demodex mite population in rosacea. J Am Acad Dermatol. 1993;28:443-448.
9. Erbagci Z, Ozgoztasi O. The significance of Demodex folliculorum density in rosacea. Int J Dermatol. 1998;37: 421-425.

10. Vance J. Demodicidosis-do Demodex mites cause disease? Curr Conc Skin Disorder. 1986;10-18.

11. Diazperez J. Demodex mites in rosacea. J Am Acad Dermatol. 1994;30:812-813.

12. Li J, O'Reilly N, Sheha H, et al. Correlation between ocular Demodex infestation and serum immunoreactivity to Bacillus proteins in patients with facial rosacea. Ophthalmology. 2010; 117:870-871.

13. Holmes A. Potential role of microorganisms in the pathogenesis of rosacea. J Am Acad Dermatol. 2013;69:1025-1032.

14. Dahl MV, Ross AJ, Schlievert PM. Temperature regulates bacterial protein production: possible role in rosacea. $\mathrm{J} \mathrm{Am}$ Acad Dermatol. 2004;50:266-272.

15. Whitfeld M, Gunasingam N, Joo Leow L, Shirato K, Preda V. Staphylococcus epidermidis: a possible role in the pustules of rosacea. J Am Acad Dermatol. 2011;64:49-52.

16. Lacey N, Delaney S, Kavanagh K, Powell FC. Mite-related bacterial antigens stimulate inflammatory cells in rosacea. $\mathrm{BrJ}$ Dermatol. 2007;157:474-481.

17. Szkaradkiewicz A, Chudzicka-Strugała I, Karpiński TM, et al. Bacillus oleronius and Demodex mite infestation in patients with chronic blepharitis. Clin Microbiol Infect. 2012;18:10201025.

18. O'Reilly N, Bergin D, Reeves EP, McElvaney NG, Kavanagh K. Demodex-associated bacterial proteins induce neutrophil activation. Br J Dermatol. 2012;166:753-760.

19. Hozono Y, Ueta M, Hamuro J, et al. Human corneal epithelial cells respond to ocular-pathogenic, but not to nonpathogenicflagellin. Biochem Biophys Res Commun. 2006;347:238-247.

20. Maltseva I, Fleiszig SJM, Evans DJ, et al. Exposure of human corneal epithelial cells to contact lenses in vitro suppresses the upregulation of human beta-defensin- 2 in response to antigens of Pseudomonas aeruginosa. Exp Eye Res. 2007;85: 142-153.

21. O'Reilly N, Gallagher C, Katikireddy KR, Clynes M, O'Sullivan F, Kavanagh K. Demodex-associated Bacillus proteins induce an aberrant wound healing response in a corneal epithelial cell line: possible implications for corneal ulcer formation in ocular rosacea. Invest Ophthamol Vis Sci. 2012;53:32503259.

22. Wilson SE, Esposito A. Focus on molecules: interleukin-1: a master regulator of the corneal response to injury. Exp Eye Res. 2009;89:124-125.

23. Sakimoto T, Yamada A, Kanno H, Sawa M. Upregulation of tumor necrosis factor receptor 1 and TNF-alpha converting enzyme during corneal wound healing. Jpn J Ophthalmol. 2008;52:393-398.

24. Ishihara K, Hirano T. IL-6 in autoimmune disease and chronic inflammatory proliferative disease. Cytokine Growth Factor Rev. 2002;13:357-368.

25. Grellner W, Georg T, Wilske J. Quantitative analysis of proinflammatory cytokines (IL-1beta, IL-6, TNF-alpha) in human skin wounds. Forensic Sci Int. 2000;113:251-264.

26. Iocono JA, Colleran KR, Remick DG, Gillespie BW, Ehrlich HP, Garner WL. Interleukin-8 levels and activity in delayed-healing human thermal wounds. Wound Repair Regen. 2000;8:216225.

27. Oka M, Norose K, Matsushima K, Nishigori C, Herlyn M. Overexpression of IL-8 in the cornea induces ulcer formation in the SCID mouse. Br J Ophthalmol. 2006;90:612-615.

28. Li Z, Burns AR, Miller SB, Smith CW. CCL20, $\gamma \delta$ T cells, and IL22 in corneal epithelial healing. FASEB J. 2011;25:2659-2668.

29. Garreis F, Gottschalt M, Schlorf T, et al. Expression and regulation of antimicrobial peptide psoriasin (S100A7) at the 
ocular surface and in the lacrimal apparatus. Invest Ophthalmol Vis Sci. 2011;52:4914-4922.

30. Karthikeyan RS, Leal SM, Prajna NV, et al. Expression of innate and adaptive immune mediators in human corneal tissue infected with Aspergillus or fusarium. J Infect Dis. 2011;204: 942-950.

31. Prada J, Noelle B, Baatz H, Hartmann C, Pleyer U. Tumour necrosis factor alpha and interleukin 6 gene expression in keratocytes from patients with rheumatoid corneal ulcerations. Br J Ophthalmol. 2003;87:548-550.

32. Gordon GM, Ledee DR, Feuer WJ, Fini ME. Cytokines and signaling pathways regulating matrix metalloproteinase-9 (MMP-9) expression in corneal epithelial cells. J Cell Physiol. 2009;221:402-411.

33. Oka M, Norose K, Matsushima K, Nishigori C, Herlyn M. Overexpression of IL-8 in the cornea induces ulcer formation in the SCID mouse. Br J Ophthalmol. 2006;90:612-615.

34. Topcu-Yilmaz P, Atakan N, Bozkurt B, et al. Determination of tear and serum inflammatory cytokines in patients with rosacea using multiplex bead technology. Ocul Immunol. Inflamm. 2013;21:351-359.

35. Heimer SR, Yamada A, Russell H, Gilmore M. Response of corneal epithelial cells to Staphylococcus aureus. Virulence. 2010;1:223-235.

36. Li Z, Burns AR, Miller SB, Smith CW. CCL20, $\gamma \delta$ T cells, and IL22 in corneal epithelial healing. FASEB J. 2011;25:2659-2668.

37. Shirane J, Nakayama T, Nagakubo D, et al. Corneal epithelial cells and stromal keratocytes efficiently produce CC chemo- kine-ligand 20 (CCL20) and attract cells expressing its receptor CCR6 in mouse herpetic stromal keratitis. Curr Eye Res. 2004;28:297-306.

38. Huang LC, Jean D, Proske RJ, Reins RY, McDermott AM. Ocular surface expression and in vitro activity of antimicrobial peptides. Curr Eye Res. 2007;32:595-609.

39. Daniels JT, Geerling G, Alexander RA, Murphy G, Khaw PT, Saarialho-Kere U. Temporal and spatial expression of matrix metalloproteinases during wound healing of human corneal tissue. Exp Eye Res. 2003;77:653-664.

40. Mohan R, Chintala SK, Jung JC, et al. Matrix metalloproteinase gelatinase B (MMP-9) coordinates and effects epithelial regeneration. J Biol Chem. 2002;277:2065-2072.

41. Pflugfelder SC, Farley W, Luo L, et al. Matrix metalloproteinase9 knockout confers resistance to corneal epithelial barrier disruption in experimental dry eye. Am J Pathol. 2005;166: 61-71.

42. Afonso AA, Sobrin L, Monroy DC, Selzer M, Lokeshwar B, Pflugfelder SC. Tear fluid gelatinase B activity correlates with IL-1alpha concentration and fluorescein clearance in ocular rosacea. Invest Ophthalmol Vis Sci. 1995;40:2506-2512.

43. Dursun D, Kim MC, Solomon A, Pflugfelder SC. Treatment of recalcitrant recurrent corneal erosions with inhibitors of matrix metalloproteinase-9, doxycycline and corticosteroids. Am J Ophthalmol. 2001;132:8-13.

44. Fini ME, Cook JR, Mohan R. Proteolytic mechanisms in corneal ulceration and repair. Arch Dermatol Res. 1998;290:S12-S23. 